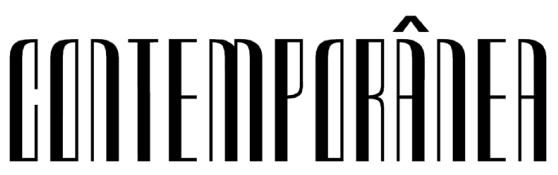

ISSN (Eletrônico): 2316-1329

http://dx.doi.org/10.4322/2316-1329.003

Contemporânea

v. 6, n. 1, p. $237-258$

Jan.-Jun. 2016

Entrevista

\section{Huw Beynon: uma sociologia pública do trabalho}

\section{Huw Beynon: a public sociologist of work}

Fernando Ramalho Martins ${ }^{1}$

Felipe Rangel $^{2}$

\section{Apresentaç̃̃o}

Huw Beynon pode ser considerado um dos mais destacados sociólogos do trabalho do Reino Unido. Com uma longa carreira de pesquisas dedicadas principalmente ao estudo empírico do trabalho industrial, acumula reconhecimentos tanto no campo acadêmico como por meio da sua atuação política. Com passagem pelas universidades de Bristol, Southern Illinois, Durham, Manchester, Beynon se aposentou em 2010 pela Universidade de Cardiff, onde fundou e dirigiu o Wales Institute of Social Economic Research Data and Methods (WISERD). Em sua longa carreira, publicou mais de 20 livros, foi reconhecido com o título de Doctor of Social Sciences pela universidade de Manchester em 1999, eleito para a Academia de Ciências Sociais do Reino Unido em 2000 e congratulado em 2013 com o título de Honorary Doctor of Letters, pela Universidade de Durham. Foi de maneira muito disponível que Beynon aceitou conceder esta entrevista, realizada em sua residência, na cidade de Abergavenny, em 15 de junho de 2015. No decorrer dessa longa conversa, ele transita por sua vasta trajetória de pesquisas empíricas, recuperando as referências teóricas e políticas que influenciaram sua produção e

\footnotetext{
${ }^{1}$ Professor Assistente e Doutor pela Universidade Estadual Paulista "Júlio de Mesquita Filho" - (UNESP) Araraquara - Brasil - fernandomartins@fclar.unesp.br

${ }^{2}$ Doutorando no Programa de Pós-graduação em Sociologia e Membro do Grupo de Estudos Trabalho e Mobilidades (GETM) da Universidade Federal de São Carlos (UFSCar) - São Carlos - Brasil - feliperangelm@ gmail.com
}

Entrevista com Huw Beynon 
confrontando os contextos de suas pesquisas com observações pertinentes ao atual momento social e econômico. A partir desse movimento, Beynon aborda questões concernentes ao papel da sociologia e sua relação com públicos mais amplos; passando pelo debate sobre a interação do sociólogo com seu campo e os sujeitos de pesquisa; política e atuação sindical; consumo e trabalho; e as possibilidades e desafios para a sociologia do trabalho no contexto contemporâneo, no qual o trabalho continua sendo um elemento estruturante na vida das pessoas, mas convive com processos intensos de flexibilização que conferem um generalizado sentimento de insegurança nos trabalhadores.

\section{Entrevista $^{3}$}

Você abriu o primeiro prefácio de Trabalhando para Ford Fom $^{4}$ C. Wright Mills defendendo que a sociologia deveria ser capaz de deixar claro por que "hoje em dia, a maioria dos homens sente que sua [...] vida é uma série de armadilhas". Naquela época você aventou a hipótese de que os sociólogos escreviam para os seus pares, produzindo sociologia para os sociólogos, "um absurdo que isola o autor dos objetos de sua obra". Em sua opinião, a sociologia tem sido capaz de superar esse isolamento?

Eu escrevi isso um bom tempo atrás. Isso foi em 1972, eu acho, e esse era um tempo onde a sociologia estava se estabelecendo no Reino Unido. Antes de 1962 havia apenas três departamentos de sociologia no Reino Unido. Em 1968, eu fui para um departamento novo em Bristol. Havia a ideia da sociologia como uma nova disciplina dentro das universidades britânicas. Nós conversávamos bastante sobre a capacidade de os sociólogos oferecerem uma visão crítica de sociedade e uma visão crítica do senso comum e uma visão crítica dos grupos desempoderados. Naquele tempo, eu estava concomitantemente lecionando e realizando a pesquisa com os trabalhadores da Ford e sentia muito fortemente que se nós quiséssemos desenvolver a sociologia como uma disciplina com capacidade de ser crítica, fazia-se necessário o engajamento com as pessoas sobre as quais se estava escrevendo. Naquela época havia um artigo muito famoso, escrito nos Estados Unidos, que dizia que os sociólogos trabalhavam com as mãos para cima e com os olhos para baixo: eles tinham as mãos para cima visando os fundos e os olhos para baixo para a população. Então, em alguma medida, o que eu estava sugerindo era algo de alguma forma romântico, mas - e eu ainda acredito nisso - era dizer que os sociólogos deveriam ter uma relação muito mais direta com o mundo em que eles estavam... particularmente com as pessoas que eles estavam pesquisando. $O$ que eu penso e o que eu sempre tento fazer é conversar com as pessoas sobre o que acontece em relação a elas. Isso é o que Michael Burawoy começou a chamar de

\footnotetext{
${ }^{3}$ A entrevista foi realizada pessoalmente por Fernando Ramalho Martins, a partir de roteiro elaborado previamente.

${ }^{4}$ BEYNON, Huw. Trabalhando para Ford: trabalhadores e sindicalistas na indústria automobilística. São Paulo, Paz e Terra, 1995.
} 
sociologia pública ${ }^{5}$, que é a ideia do engajamento com as pessoas. Ele referiu-se ao meu trabalho como uma "sociologia pública por baixo". Ele defende que a sociologia pública é construída a partir de uma robusta estrutura teórica, que você poderia chamar de uma "sociologia profissional" ou de uma "sociologia profissionalizada". E ele acredita que a sociologia pública pode ser construída a partir da sociologia profissional, e eu acho que é verdade, mas eu penso que ele subestima uma tensão existente entre o processo de profissionalização e o processo de engajamento público. Por exemplo, em relação a temas como ética; o modo como esse assunto tem sido desenvolvido como uma preocupação com as práticas das ciências sociais. Em Trabalhando para Ford eu nomeei todas as pessoas e alguém poderia dizer que isso é antiético, mas eu realmente disse a eles o que eu faria. Eles [os trabalhadores entrevistados] disseram-me que contariam para mim o que eles, de toda forma, diriam para a Ford. Então, eles estavam cientes. Eu acho que, de certo modo, esse processo de anonimidade é parte do processo de profissionalização. Às vezes, pode haver boas razões para isso, mas o modo como isso tem sido usado parece-me ser uma maneira de proteger a profissão em vez de proteger a pessoa que está sendo pesquisada. Recentemente, nós descobrimos que no Reino Unido as pessoas, em especial as pobres, estão se enchendo de serem pesquisadas. Elas dizem: "Você é o quinto que me faz essas perguntas sem que nada tenha mudado". Então, se por um lado há um esforço por parte dos sociólogos para se engajar mais, como exemplificado pelo modo como a ideia de sociologia pública tem tomado conta da imaginação das pessoas, por outro, ainda há problemas. $\mathrm{O}$ estilo da escrita e a complexidade de uma linguagem altamente profissionalizada são dois problemas para se levar a sociologia para um público não sociológico. Quando eu citei Wright Mills, eu estava sendo crítico de seu famoso e excelente livro denominado The Sociological Imagination, no qual ele concentra-se no "caráter artesanal do trabalho intelectual" e, em alguma medida, isso faz parte do trabalho de um sociólogo. O que eu pensava, e ainda penso, era que precisávamos ir além desse trabalho artesanal, nós também precisamos de engajamento.

Na sua tentativa de lidar com o problema do isolamento entre o sociólogo e seu sujeito de pesquisa, você nos ofereceu um livro que nos revelou os trabalhadores e uma fábrica em seu contexto real. Você não tentou alterar as palavras dos trabalhadores para que parecessem mais formais ou "acadêmicas" e você evidenciou uma série de histórias de trabalho (como aquela sobre o rapaz que morreu no chão de fábrica e cujo corpo ficou estendido lá por um bom tempo, a fim de que a linha não parasse; ou então aquele outro que desenvolveu uma maneira especial de enganar a gerência para poder falar enquanto trabalhava, o que lhe trouxe um problema fisiológico com o passar dos anos). Como consequência

${ }^{5}$ BURAWOY, Michael. Por uma sociologia pública. Revista de Ciências Sociais, Políticas \& Trabalho. João Pessoa, n. 25, 2006, pp. 9-50. 


\section{por ter desfetichizado as relações de trabalho, você recebeu uma série de críticas. Você acha que hoje a recepção de seu trabalho seria diferente? Para melhor ou pior? Quais foram as principais lições que você tirou após a produção desse livro? Os rapazes de Halewood teriam algo a nos dizer hoje?}

Suponho que o modo como eu escrevi Trabalhando para Ford veio do sentimento de que era preciso mais engajamento entre os sociólogos e seus sujeitos de pesquisa, quando aqueles realizavam o trabalho de coleta de dados e análise do comportamento destes. Eu estava preocupado em não superteorizar isso. Embora o livro tenha uma certa estrutura teórica, esta não é evidente. E eu suponho que estava muito preocupado em desenvolver a ideia da experiência de trabalho como uma característica central do livro e da análise: como o trabalho era vivenciado e como as pessoas lidavam com isso; como as pessoas resistiam e organizavam a resistência; como elas entendiam o que estavam fazendo. Por isso, há no texto várias palavras que são as palavras das pessoas.

Eu fui treinado em uma vertente muito positivista, acho. Era muito envolvido com métodos quantitativos, mas eu também era muito interessado em etnografia. Fui treinado para analisar e categorizar as respostas, e então redigir com uma linguagem diferente. Eu sentia que isso era um dos problemas [da sociologia]. Então, em Trabalhando para Ford eu tentei encontrar um estilo de escrita que transmitisse a intensidade da fala dos homens ao relatarem suas experiências de trabalho na linha de produção. Dessa forma, em vez de citar alguém e categorizar seu comentário (dizendo: "o que foi dito aqui foi um exemplo de X ou Y"), eu tentei me engajar no discurso do sujeito e capturar a natureza da experiência de trabalho. Seria possível dizer que me permiti ser capturado por esta. Mas eu tinha que manter uma estrutura analítica, e suponho que eu tenha começado a ver as histórias ganhando seu lugar no livro. E você está certo, várias pessoas não gostaram disso. A empresa certamente não gostou disso. O livro foi publicado pela Penguin Books, em brochura, e se esgotou em nove meses. E muitas e muitas pessoas o leram. Eu tinha várias e várias cartas de trabalhadores de fábrica dizendo: "É exatamente assim que é!". Mas o livro não havia sido vastamente avaliado em periódicos de sociologia; e, em muitos aspectos, não se tratava de uma narrativa ortodoxa... Mas com o passar do tempo ele se tornou mais influente. Ele foi selecionado como texto-base para um curso da Open University Foundation e muitas pessoas, consequentemente, o estudaram. Quando de sua segunda edição, em 1975, começou-se a escrever sobre o livro como sendo uma leitura "clássica" - eu me lembro de Stuart Hall introduzindo-o dessa maneira em uma palestra minha em Londres. Então, em certo sentido, o livro adentrou à sociologia e foi absorvido por ela. Certamente ele foi muito influente no desenvolvimento de um tipo diferente de sociologia do trabalho, uma que proporcionava um entendimento do mundo do trabalhador. Estudos desse tipo têm se tornado frequentes hoje em dia com os relatos de trabalho de call centers e dos armazéns da Amazon, realizados não só por sociólogos mas também por jornalistas. Mas eu acho que a ideia de 
uma escrita embasada nas experiências cotidianas das pessoas em seus locais de trabalho é um elemento residual que ainda compõe a sociologia do trabalho.

De forma geral, a situação em Halewood hoje é muito diferente. A planta de transmissão é altamente automatizada, com grande uso de robôs. E é claro que a Ford assumiu a Jaguar e a Land Rover visando construir um novo tipo de prestígio, baseado em carros de alto valor na linha de montagem. A Ford, então, os vendeu para a Tata Steel e continua a produzir o Range Rover na planta PTA com um número muito menor de trabalhadores que em 1966. Surpreendentemente, a Ford não mais produz carros no Reino Unido. Hoje ela produz carros na Alemanha, Checoslováquia, Espanha e França. Embora a General Motors permaneça [no Reino Unido], todos os outros carros produzidos no Reino Unido derivam de plantas japonesas. Não há uma fábrica de carros britânica. A British Leyland desmoronou e, ao cabo, foi vendida para a Shanghai Motor Corporation.

Houve um encontro alguns anos atrás para discutirmos Trabalhando para Ford, para avaliarmos se ainda existe isso de trabalhando para Ford e como isso era visto. Parte da discussão foi sobre o movimento de resistência que eu descrevi no livro, e sobre como era possível mantê-lo em face da constante ameaça de a companhia mudar para outro local. Sindicalistas da GM disseram "nós temos a produção enxuta e temos que lidar com isso ou eles levarão a planta para a Alemanha”. Então, há o medo desse "voo corporativo" [corporate flight], da internacionalização de toda a companhia. Isso tem se tornado um fenômeno universal com trabalhadores da região do $\mathrm{ABC}$ vendo novas plantas e investimentos sendo alocadas longe de São Paulo, e indo para Recife, Bahia, Resende e por aí vai.

Isso foi o que aconteceu em Liverpool e na segunda edição do livro eu escrevi sobre as maneiras com que esta incerteza adentrou a força de trabalho, com a companhia efetivamente colando trabalhadores de diferentes plantas em competição uns com os outros.

Então, de várias maneiras, o livro foi um sucesso, eu acho. Talvez ele não esgotasse caso fosse publicado hoje. Certa vez, conversei com um editor e ele me disse que hoje provavelmente eles nem mesmo publicariam Trabalhando para Ford porque: quem estaria interessado em comprar um desses livros baseados nos pormenores do trabalho fabril?

\section{Ele disse isso?!}

Sim, ele disse. O editor da Sage disse que se alguém lhes trouxesse um livro como Trabalhando para Ford, hoje, eles não o publicariam porque não há mercado para ele. Isso reflete o fato de que o mercado editorial mudou e que, crescentemente, o mercado de livros de sociologia favorece os livros que podem ser usados para ensinar alunos, livros-texto de diferentes tipos, livros de metodologia e por aí vai. Eu acho que isso faz parte do processo de profissionalização e de vinculação da sociologia à academia e não às ruas e aos locais de trabalho. Talvez nos dias de hoje as pessoas possam fazer diferente por meio das publicações eletrônicas e dos websites. 
Mas eu discordo dessa opinião. Ainda se trata de um ótimo livro para ser usado em sala de aula, quando eu uso esse livro, meus alunos o adoram, pois eles conseguem ter a ideia do que era trabalhar para a Ford, de que os trabalhadores muitas vezes não desejavam comprar carros da Ford mesmo com desconto, pois o carro os remetia às suas condições de trabalho. Eles gostam muito do livro.

Isso é interessante, porque eu sei que os administradores da Ford usaram o livro para treinamento dos supervisores nos anos de 1980, e que ele foi bastante influente em mudar a maneira como a companhia pensava sua "gestão". Um dos meus amigos que lecionam em uma escola de negócios usa o livro com frequência e ele comentou sobre uma discussão muito interessante acerca de uma parte do livro onde um homem afirma sempre procurar deixar o trabalho melhor "para a próxima pessoa". Os estudantes não entenderam por que isso seria verdade, porque isso vai de encontro a todas as teorias econômicas do autointeresse individual. Esse exemplo foi tomado como um bom exemplo de como um "interesse coletivo" pode ocorrer na vida diária. Quando você se vê no outro e o outro em você. E isso é muito difícil para pessoas que não tiveram tais experiências e não entendem o que é a consciência coletiva: que você concorda em fazer o que os outros querem, mesmo que você não queira. E tem se tornado mais difícil falar sobre isso atualmente, porque há uma grande tentativa de romper com isso; politicamente romper com os processos - material e ideologicamente - que criam esse tipo de consciência.

Em 1977, você e Theo Nichols tentaram novamente dar voz aos trabalhadores. Eu gostaria de ler uma notável parte de Living with capitalism $^{6}$ e ouvir seu comentário sobre ela:

Há muito pouco 'prazer' para ser desfrutado em Riverside - e infelizmente, a falta de propósito que 'surpreendeu' a Grã-Bretanha não deve ser motivo de surpresa. Não se você considerar as vidas que estes homens levaram; as escolas que participaram; os postos de trabalho que eles tiveram acesso. Eles foram produzidos por uma existência sem propósito. A escolha de vida deles foi a 'escolha' de trabalhar em Riverside, ou em outro lugar como este, e se, por um lado, em Riverside eles conseguem 'um pouco a mais', por outro, as coisas estão estruturadas de tal forma que eles não têm voz nas decisões importantes sobre os propósitos finais. Estas são as próprias decisões que a gestão e os políticos não vão deixar, e não podemos deixar para eles. De fato, pois a 'falta de propósito' não é nenhuma surpresa. Não, se você pensar sobre essas coisas por um momento, e multiplicar por gerações (Nichols; Beynon, 1977: 201, tradução livre).

${ }^{6}$ NICHOLS, Theo; BEYNON, Huw. Living with capitalism. Londres, Routledge \& Kegan Paul Ltd., 1977. 
As coisas estão diferentes no Reino Unido? Os trabalhadores de Riverside e dos arredores têm tido uma vida com mais propósito e mais voz nas fábricas e na política? Ou o mencionado processo multiplicador persiste?

Bem, se eu tivesse que escolher eu diria que o processo persiste. Obviamente houve mudanças, e há muitos tipos diferentes de trabalho hoje; mas muitos desses processos persistem. Por exemplo, um rapaz que entrega comida passou aqui ontem e disse: "Eu não estaria aqui novamente se o meu gerente não tivesse me ordenado". Então eu disse: "Por que isso?", e ele respondeu: "Porque eu tenho muitos afastamentos". E eu disse: "Bem, você não pode evitar ficar doente", e ele respondeu: "Bem, essa não é a maneira que eles veem as coisas. Eles contarão todos os meus dias de afastamento e quando eu voltar eles irão me demitir". Então eu disse: "Você deveria dizer a eles que eles deveriam lhe tratar com mais dignidade". Ele, então, concluiu: "Não há dignidade em ser um trabalhador manual neste país". Um outro rapaz que conheço possui um "contrato de zero horas" com uma agência de empregos e presta serviços para uma gigante do setor alimentício, a Unilever Best Foods. Ele trabalho no turno da noite, na linha de produção. Ele me confidenciou que aquilo é pior do que a situação que eu descrevi em Trabalhando para Ford. Eles são, de fato, tratados como números, porque não possuem um sindicato bem organizado. E ele me descreveu os serviços, o local e a repetitividade e a falta de sentido daquilo tudo, bem como o fato de ele não saber de uma semana para outra quando trabalhará, quantos turnos ou que serviço realizará. Atualmente, mais de um milhão de pessoas no Reino Unido trabalha sob "contrato de zero horas". Portanto, certamente há exemplos de trabalho sem sentido.

O que mudou um pouco, eu suponho, é que aqueles dois livros que você mencionou referem-se a trabalhadores homens e, basicamente, da manufatura. Quando nós escrevemos Living with Capitalism, havia cerca de 5 milhões de postos de trabalho no setor manufatureiro, e hoje há menos de um milhão. Eu acredito que menos de $10 \%$ do PIB do Reino Unido vem da manufatura. Houve uma perda de 3 milhões de postos de trabalho durante os primeiros três anos do governo de Margaret Thatcher. Portanto, esses tipos de trabalho se foram. Eles foram substituídos por dois processos: primeiro, pelo aumento do trabalho no setor de serviço, e parcialmente por meio da terceirização; e, segundo, pelo aumento na proporção de mulheres na força de trabalho. Agora, a força de trabalho é quase equivalente em termos de gênero e em alguns lugares como aqui [País de Gales] há mais mulheres do que homens na força de trabalho. E há uma grande variedade de trabalhos associados ao emprego no serviço público.

Além disso, um número muito maior de pessoas possui nível universitário de educação, aqui no Reino Unido. Então, mais pessoas vão para a universidade. Mas aí você se dá conta de que, certamente, muitas destas, após um ano da sua graduação, estarão empregadas em trabalhos que não exigem graduação, e trabalharão na Tesco ou em call centers. Muitos, mas muitos deles, estão trabalhando em call centers. Muitos destes estão trabalhando em call centers 
cujo processo de trabalho tem sido chamado de "linha de produção na cabeça", assim que uma ligação termina outra se inicia.

Nos anos de 1970 (quando eu e Theo estávamos trabalhando juntos em Bristol) houve considerável discussão sobre as novas formas de reorganizar os trabalhos e os empregos. Algumas pessoas achavam que as novas tecnologias associadas às novas filosofias gerenciais pós-fordistas produziriam mudanças significativas e trariam mais sentido para a vida dos trabalhadores. Não é de todo claro se essas promessas foram cumpridas. Na verdade, para muitos, parece que o "sentido" de um trabalho advém da ameaça de perdê-lo. Foi nesse sentido que eu escrevi um capítulo adicional para a segunda edição de Trabalhando para Ford e o chamei como segue: "Faça o que lhe mandam: qual a estratégia para o trabalho?".

Então, se por um lado houve mudanças no trabalho, por outro, houve tanta continuidade quanto ruptura. Eu acho que ainda há algo naquela estrutura de análise que nos diz algo sobre como a classe é formada, por meio: dos pais; do lugar onde você nasce; das escolas que você frequenta; dos lugares onde trabalha e dos lugares onde vive. Estas continuam sendo fontes muito fortes de entendimentos de mundo. Particularmente quando são reforçadas por lugares comuns de trabalho ou estudo. É claro que há muita fragmentação, e talvez exista um enfraquecimento do senso geral de solidariedade da classe trabalhadora, mas (curiosamente) para os trabalhadores manuais não houve nenhuma melhoria no sentido deles sentirem-se no controle das suas atividades laborais ou de assuntos relevantes que afetam suas vidas.

Eu não estou certo de que isso se aplica apenas para os trabalhadores manuais. A percepção de "perda" no lugar de "ganho" de controle sobre sua vida laboral parece também afetar empregados de escritórios e os ditos profissionais - doutores e professores universitários! Na universidade nós costumávamos pensar que estávamos no controle de nossas aulas, de nossa pesquisa, bem como no modo como organizávamos os departamentos e por aí vai. Isso mudou drasticamente. Ainda há um certo grau de "liberdade acadêmica", mas há muita regulação e monitoramento do que se faz; mudanças contratuais em relação a quem pode fazer propostas de pesquisa e em relação às pensões. Algumas pessoas têm escrito sobre a "proletarização" da academia!

Braverman teve um grande impacto na sociologia do trabalho, sobretudo no Reino Unido. Como você avalia as ideias deste autor à luz do mundo contemporâneo? Como consequência do trabalho de Braverman ${ }^{7}$, houve o desenvolvimento da Labour Process Theory especialmente no Reino Unido. Você tem tido contato com os autores dessa corrente? Quais são suas potencialidades e limitações?

Essa é uma questão difícil. Eu penso que o livro do Braverman foi um livro muito importante e interessante ao usar Marx para prover um entendimento detalhado do Taylorismo e de seu impacto sobre o trabalho no século XX. Eu estou lendo um 
livro sobre o modo em que a indústria de corte de diamante foi levada da Bélgica para a China e agora para a Índia. Eu estou lendo como eles mudaram o processo de trabalho para tê-lo executado por várias pessoas em vez de tê-lo executado por um trabalhador qualificado; e é como se isso tivesse saído das páginas do livro do Braverman: esse processo de extração do conhecimento, de desqualificação e da organização do trabalho. Portanto, foi um livro muito importante e ainda é muito importante nos dias de hoje, embora esteja um pouco fora de moda, porque, de um modo estranho, o Taylorismo foi substituído, no discurso acadêmico, pelo Fordismo; então veio o debate pós-fordista e o debate da desqualificação (que tinha se tornado um tanto quanto limitado talvez) se perdeu. Inquestionavelmente, trata-se de um livro importante e que obteve um impacto significativo abrindo espaço para a ideia de "processo de trabalho" e de mudança nos locais de trabalho como sendo áreas de análise teórica e empiricamente importantes. Michael Wood foi uma das figuras-chave nesse desenvolvimento e eu conversei com ele em uma conferência em São Paulo há 25 anos, quando discutíamos a desqualificação e ele era muito cético em relação a isso. Então, é claro, a Labour Process Conference ${ }^{8}$ foi criada e se tornou um eventual anual contínuo e de muito sucesso.

Há problemas, eu acho. Por exemplo, houve uma tendência em centrar as análises e os debates no conceito de "desqualificação" que se transformou numa espécie de lei universal, uma fórmula de pesquisa. Perderam-se de vista outras coisas, sabe? John Berger - o famoso crítico de arte, fotógrafo e historiador - escreve sobre problema relacionado ao fotógrafo que fica preso ao enquadramento da imagem, preso às lentes da câmera. Ele escreve sobre como o fato de você passear com o seu cachorro, enquanto este salta de cá pra lá e de lá pra cá, faz com que você olhe para além do enquadramento, oferecendo-lhe uma maneira mais ampla de ver as coisas. O Trabalhando para Ford contém a análise do processo de trabalho em si. A estrutura é de fato ampla, de forma a possibilitar a observação de uma série de outras coisas relacionadas à experiência de trabalho. É nessa direção que eu acho que o livro do Braverman foi muito importante, mas, na condução de análises de locais de trabalho [inspiradas nesse referencial], estas tenderam a ofertar narrativas descontextualizadas. Elas tornaram-se monocromáticas, se preferir.

Mas a Labour Process Analysis foi um passo importante e no Reino Unido foi desenvolvida de modo mais acentuado no contexto das escolas de negócio em vez de nos departamentos de sociologia. Isso ajudou a expor os locais de trabalho a análises críticas, mostrando que compreender o que acontecia nos locais de trabalho era importante para entender o tipo de sociedade em que vivemos.

\section{Em um artigo sobre a grande depressão no Reino Unido você mostra como o "gradualismo" foi usado tanto pelo governo trabalhista (com MacDonald) quanto pelo governo conservador (com Baldwin), durante um momento de crise econômica. Corte de gastos públicos e}

${ }^{8}$ Vide: INTERNATIONAL LABOUR PROCESS CONFERENCE - ILPC. Berlin. Disponível em: <http://www. ilpc.org.uk/>. Acesso em: 03 out. 2015. 
de benefícios foram as principais estratégias de recuperação econômica. Mencionando um romance de Raymond Williams [Second Generation] ${ }^{9}$, no qual este descreve o fluxo migratório de mineiros desempregados, você diz algo assim: "Essa mobilidade de trabalhadores estava alinhada a uma filosofia de mercado de um governo que priorizava o capital como um elemento-chave no processo de decisão política, e ao qual o mercado de trabalho precisava se ajustar" (p. 291) ${ }^{10}$. Isso me levou ao seguinte pensamento: "Espere um pouco, ele está realmente falando de um tempo passado?". O que concretamente mudou e o que permaneceu em termos políticos para o trabalho e para as políticas trabalhistas deste então? Como o Partido Trabalhista (e outros similares) têm mudado em termos de sua abordagem política?

Esta é uma pergunta triste que você me faz. Eu estive em um encontro em Manchester há dois meses e houve uma longa discussão sobre o que aconteceria e alguém disse-me: "Eu li seu artigo sobre a década de 1930 e o que você disse lá me fez pensar que nós iremos ter um longo período de governo conservador novamente". E eu disse: "Eu acho que provavelmente nós iremos". Historiadores do trabalho afirmam haver um estranho problema eleitoral que é: se você estiver no controle quando as coisas desandam, as pessoas irão culpá-lo por isso. Em 1929 e em 2008 houve um governo trabalhista; e nos Estados Unidos em ambas as ocasiões houve um governo republicano. E foi bastante curioso. $\mathrm{O}$ homem que estava falando comigo disse que Roosevelt apenas foi capaz de pactuar o New Deal porque ele não havia sido "pego", porque ele não havia produzido a depressão; e, dessa forma, ele pôde propor uma alternativa. Eu acho que há um processo político como esse ocorrendo. Todavia, há também a questão do Partido Trabalhista do Reino Unido e seu comprometimento com o que Ralph Miliband chama de "Socialismo Parlamentar", uma abordagem gradualista que separa a representação parlamentar da luta diária dos trabalhadores.

E nesta última eleição, há uma série de coisas que vale a pena ser lembrada, $\mathrm{e}$ uma delas é que o líder trabalhista foi criticado por se posicionar muito à esquerda, quando, de fato, havia muito pouco em seu programa que seria considerado de esquerda há 20 anos. É uma espécie muito leve de social-democracia, com uma ideia de que vocêtem que controlar os preços que as empresas cobram pela energia, algo que com o advento do neoliberalismo tornou-se impensável. A segunda coisa é que, em toda a discussão da eleição, todas as coisas que conversamos, ou melhor, nenhuma das coisas que discutimos aqui hoje foram levantadas por nenhum partido político; os sindicatos foram mencionados uma vez, no entanto, tão logo os conservadores ganharam, eles anunciaram que restringiriam as regras

\footnotetext{
${ }^{9}$ WILLIAMS, Raymond. Second generation. Londres, The Hogarth Press, 1988.

${ }^{10}$ BEYNON, Huw. O paradoxo inglês. In: LIMONCIC, Flávio; MARTINHO, Francisco Carlos Palomanes (Orgs.). A Grande Depressão: política e economia na década de 1930. Rio de Janeiro, Civilização Brasileira, 2009, pp. 277-304.
} 
concernentes às eleições sindicais e aos piquetes. A ideia de internacionalização do trabalho, o tipo de emprego que as pessoas têm e o futuro do trabalho não chegaram nem perto da agenda. Assim, parece-me que os partidos tentam conduzir um pouco o conflito entre capital e trabalho, e com as regras que são regulamentadas por eles se estreitando cada vez mais quando há uma crise. E na crise estas precisam servir o capital.

Então, eu acho que você está certo em dizer: “espere um pouco!”. Eu acho que a situação atual é muito similar à dos anos de 1930 de várias maneiras. Eu tenho pensado que desde que eu escrevi aquele artigo houve uma série de similaridades. Assim como nos anos de 1930, o governo tem desferido ataques sobre a população pobre, que tem sido retratada como displicente, indigna e superdependente do Estado de bem-estar social, que (arbitrariamente) tem recebido cortes visando salvar a eles e a economia! Portanto, há grandes similaridades e este é caso em cada uma das Grandes Depressões em que o Partido Trabalhista não cuidou da classe trabalhadora.

Em 2011, quando você foi homenageado por suas contribuições para a sociologia do trabalho pela UFRJ, foi dito que sua primeira vinda ao Brasil ocorreu depois que E. P. Thompson teve seu visto negado pelo governo militar brasileiro. Você poderia confirmar esta história e comentar sobre a influência desse autor em seu trabalho?

Foi Michael Hall, eu acho. Eu não sabia disso até Michael mencionar. Eu conhecia Edward Thompson muito bem e por incrível que pareça o encontrei pela primeira vez nos Estados Unidos, quando estive com ele em Pittsburgh em 1974. Eu estava na Universidade de Illinois e ele na Universidade de Pittsburgh e nos tornamos amigos próximos após um tempo. Ele já era bastante influente quando eu o encontrei. A Formação da Classe Operária Inglesa foi certamente um livro brilhante, mas seu envolvimento em uma série de debates sobre teoria social e de classes foi muito importante. Seu engajamento com os estruturalistas franceses e com a interpretação da história inglesa da nova esquerda foram momentos muito importantes. Ele era um intelectual público engajado (não gostava muito da sociologia) e era envolvido com discussões teóricas num sentido político amplo, para além da academia. O que eu aprendi com ele foi sua ênfase na "experiência" e a ideia de que a "experiência" tem algo que os sociólogos podem usar como uma estrutura para entender a classe e seu devir. Você não pode construir uma descrição da classe sem incluir a experiência diária das pessoas. E ele fez isso basicamente por meio de documentos históricos. Ele escreveu que "a experiência salta das páginas”. O que difere para os sociólogos é o como você se engaja na experiência, isto é, nas experiências dos outros: como você se envolve com estes e como você se apossa dessa experiência. De alguma maneira, você tem que se envolver com ela, penso eu. E isso me conduz ao meu tema, isto é, a falar e estar com as pessoas.

Há um livro que foi muito influente para mim. Ele foi escrito por Alvin Gouldner, que assim procedeu. O livro, baseado em sua tese de doutorado, chama-se Wildcat 
Strike ${ }^{11}$ - na verdade o seu principal livro chamou-se Patterns of Industrial Bureaucracy ${ }^{12}$. E ele escreve o livro com base em sua experiência em uma mina de gesso - onde ele se volta para a seguinte reflexão: como você pode se apossar da experiência? Ele afirma ter se convencido de que há pessoas que você não pode entrevistar antes de se tornar próximo a elas. Isso requer que você: esteja com elas, goste delas, fale com elas. Elas exigem que você responda suas questões e que sintam-se bem na sua companhia; e, sem isso, elas não falarão com você. Isso é dificilmente mencionado nos livros contemporâneos de metodologia de pesquisa. Essa é a maneira pela qual você obtém suas respostas e o resto. Se você aparece como uma pessoa externa, que vem para fazer questões, então elas não lhe responderão. Uma série de pessoas não o levará a sério. Então foi esse tipo de ideia que eu tomei de Edward Thompson. Era isso que estava em minha mente quando eu concebi o livro Trabalhando para Ford. Suas ideias também me ajudaram em minha pesquisa sobre o sindicalismo mineiro.

Quando ao fui ao Brasil pela primeira vez, tinha acabado de escrever Masters and Servants ${ }^{13}$ e no cerne desse livro há o fato de que em 1872, um século após o início da Revolução Industrial, os mineiros em Durhma ainda eram definidos legalmente como "trabalhadores servis" e não como trabalhadores assalariados livres. O ponto que defendemos nesse livro foi que as classes trabalhadoras são formadas de diferentes maneiras e que a classe trabalhadora inglesa - que foi vista a partir dos escritos de Marx como um "caso clássico" - possuía em seu bojo uma ocupação central (na verdade a maior ocupação) composta por trabalho não livre.

Isso foi visto como muito interessante no contexto brasileiro, onde havia uma ideia de que a classe trabalhadora brasileira não era uma classe trabalhadora pura, por possuir em seu âmago um grande número de "trabalho forçado" e de emprego informal. A abordagem relativista de Thompson - segundo a qual há mais de uma maneira de se formar a consciência de classe - pode ser desdobrada para a ideia de que há mais de um caminho para a formação de uma classe trabalhadora. Faz-se necessário tomar cuidado para que isso seja sustentado por alguma explicação estrutural, eu acho. Mas as ideias de que há diferentes maneiras de se formar a consciência de classe e de que há diferentes maneiras de se formar a classe trabalhadora são de fato centrais para o meu trabalho.

Então você concorda com a discussão de E. P. Thompson ${ }^{14}$ sobre classe, quando ele coloca essa categoria dentro de uma perspectiva histórica e relacional, correto? E o que é consciência de classe para você e qual a importância desse conceito para a sociologia do trabalho?

\footnotetext{
${ }^{11}$ GOLDNER, Alvin. Wildcat strike. Yellow Springs, Antioch Press, 1954. 12 Patterns of industrial bureaucracy. Glencoe, Free Press, 1954.
}

${ }^{13}$ BEYNON, Huw; AUSTRIN, Terry. Masters and servants: class and patronage in the making of a labour organisation. Londres, Rivers Oram Press, 1994.

${ }^{14}$ THOMPSON, Edward. A formação da classe operária. Rio de Janeiro, Paz e Terra, 1987. 
Bem, ele trabalhou a questão da consciência de classe e ele é muito claro sobre isso, mas também muito impreciso, às vezes. Eu lembro que ele estava indo para uma aula em Pittsburgh e perguntei: “Por que você está tão nervoso?”. Ele disse: "Bem, eu ainda não estou certo sobre isso, se eu realmente entendo acerca do que vou falar”. Essa imprecisão, eu acho, relaciona-se a sua maneira fluida pela qual ele veio a entender a classe social... e como é muito mais difícil explicar isso do que recorrer a uma abordagem que reduz classe a conjuntos de categorias de emprego!

Ele via "classe" como um processo, e pensava que as classes tinham que ser estudadas em relação umas às outras e ao longo do tempo. Essa foi a origem de seu desacordo com as abordagens sociológicas da estratificação social. Para ele, a sociologia "para a máquina do tempo". Em sua visão, "consciência de classe", ou qualquer forma de consciência, é algo que emerge a partir de relações que devem ser estudadas ao longo do tempo. Assim, em algumas partes isso se torna tão fluido que é muito difícil saber como proceder. Mas isso certamente me fez pensar que a sociologia - voltando para Trabalhando para Ford - precisava ter uma visão mais ampla. É por isso que o livro começa com Detroit e Dagenham e tenta situar esse tipo de relação entre a Ford Company e sua força de trabalho, ao longo do tempo, historicamente, e particularmente com o caso "Halewood"; e, com isso, transmitir a ideia de classes e relações [de classe]. Eu acredito que o conceito que foi produzido foi algo que eu chamei de "consciência de classe fabril". Em certo sentido, é possível afirmar que isso se encaixa nas ideias de Thompson e as desenvolve, sobretudo na medida em que se evidencia uma forma de consciência de classe, um certo reconhecimento de ser o trabalhador, uma consciência de que "eles nos tratam como números". Isso apareceu muito acentuadamente nos questionamentos à gerência, onde eles [os administradores] foram muito claros sobre o que pensavam no tocante às suas relações, apontadas como conflitivas.

Mas quando eu perguntava às pessoas sobre o que elas fariam, em relação a um novo tipo de sociedade ou para onde caminharíamos, havia uma militância que era, na verdade, fabril. Ela não levava a nenhum tipo de visão articulada de transformação. Na ausência de um partido hegemônico, o Partido Trabalhista não conduzia a nenhum tipo de ideia transformadora. E, de certo modo, isso se tornou o problema principal, porque quando eles se colocaram contra... quando esse tipo de organização militante colocou-se contra o fechamento e a realocação das fábricas para outros países, a política fabril, essa consciência de classe, não ofereceu a eles uma resposta. Eles [os militantes] podiam combater o chefe, mas eles não podiam combater o chefe quando este se mudava para algum outro canto do mundo. Eles não sabiam como impedir que este se mudasse levando o trabalho consigo. Se o chefe estivesse lá, eles lutariam, mas quando este decide ir para o exterior, isso se torna impossível. Assim, o movimento dos representantes sindicais, sobre o qual eu escrevi, não pôde lidar com as mudanças na estratégia corporativa, que foram subvencionadas pelo governo Thatcher no início dos anos de 1980 .

Eles [os representantes sindicais] de fato desenvolveram comitês combinados de representantes sindicais que os ligavam a representantes de outras plantas 
industriais ao redor da Europa e do mundo. Esses comitês tentaram combater essa mobilidade do capital. E hoje esse movimento pode ser visto como uma grande referência.

Todavia, a Ford e outras companhias de carro desenvolveram uma sofisticada resposta a eles: basicamente começaram a estimular um disputa entre trabalhadores de fábricas diferentes, por meio da publicação de dados diários de produção. Então, os supervisores podiam dizer: "Veja, é melhor melhorarmos amanhã. Veja quanto eles produziram!"; ou “Eles não são tão bons quanto nós, nós produzimos muito mais e, portanto, a fábrica deles deveria ser fechada e não a nossa”. E isso tinha um impacto.

Há uma música de Bruce Springsteen sobre Johnny 99 que trata do fechamento da fábrica da Ford Mahwah em New Jersey. Naquela fábrica, quando os trabalhadores protestaram contra o seu fechamento, eles disseram: "Por que vocês estão nos fechando, por que não fecham Halewood?”. Eles sabiam que Halewood produzia menos carros. Então, em crises, essa estratégia da companhia ajudava a produzir divisões entre os trabalhadores e uma quebra da consciência de classe universal. Isso estava acontecendo quando eu escrevia Trabalhando para Ford. Desde seus primeiros dias em Halewood a companhia tentava organizar os trabalhadores uns contra os outros, tanto via pressão quanto via controle dos canais do capital internacional. Em Cologne a companhia empregava trabalhadores migrantes e eles diziam: "Isso é o que eles podem produzir, por que vocês produzem tão pouco?". Os representantes sindicais passaram a se referir a isso como "a palmatória de Cologne"; uma medida de resultado advinda de plantas compostas por trabalhadores imigrantes, sendo usados para aumentar a taxa de exploração em toda a companhia.

Alguns autores defendem que vivemos um “capitalismo flexível”, no qual as pessoas nem mesmo têm tempo para formar um caráter por meio de seu trabalho e de suas relações de trabalho, no qual a terceirização tem segregado ainda mais os trabalhadores, no qual as pessoas tendem a se identificar mais como consumidores do que como trabalhadores. Você concorda com essa análise? Eu gostaria de saber sua opinião sobre as mudanças na nossa corrente na sociedade e como elas afetam o mundo dos trabalhadores. Como você prevê o futuro do sindicalismo?

Bem, embora exista uma série de verdades nessas explicações, eu não acho que tenhamos uma sociologia boa o suficiente em relação à atual situação do trabalho. Parcialmente, porque a sociologia, 30 anos atrás, foi capaz de produzir explicações baseadas em um certo número de grandes indústrias. Obviamente as indústrias predominantes eram as de carvão, de automóvel, químicas e por aí vai. Hoje o trabalho se tornou muito mais fragmentado. Portanto, nós precisamos, de certo modo, de um número maior de estudos e talvez haja muito mais dificuldade para se fazer isso, porque está cada vez mais difícil acessar os locais de trabalho para investigá-los. Nós precisamos desenvolver maneiras para se olhar para esses diferentes [trabalhos]. 
Por exemplo, uma das coisas que têm atraído a atenção pública no Reino Unido é o fato de que muitos e muitos jovens se embriagam durante as noites de sexta e sábado. E essa "cultura da farra" tem sido registrada. Muitas e muitas festas de fim de semana... Nenhuma das explicações que eu li relaciona esse comportamento ao trabalho que estes jovens desempenham. Não sei, mas eu imagino que os rapazes e moças liberam sua energia após uma semana de trabalho sem sentido. E certamente houve grande aumento no consumo [de bebidas] e um grande declínio do sindicalismo. E, associado a isso, no Reino Unido houve um crescimento astronômico nos débitos pessoais. Como você pode notar, há a emergência de uma grande variedade de estilos de vida que têm por base o consumo em lugar do local de trabalho; mas o trabalho permanece significante e muito do consumo é baseado no débito - mesmo após a crise de 2008, com a estagnação salarial, o débito pessoal cresceu. Raymond Williams quando escreveu sobre os anos de 1960 disse que uma das maiores preocupações sobre o futuro da classe trabalhadora inglesa era o problema com o débito.

\section{Débito?}

Sim, débito! Eu escrevi em Trabalhando para Ford sobre os representantes sindicais agindo como líderes. Eles falavam bastante sobre a importância de não se contrair dívida para compra de casa própria e da preferência de que suas mulheres não trabalhassem, porque eles tinham de ser isentos de débito e tão dependentes do salário da Ford quanto todos os outros trabalhadores. Assim, se houvesse uma greve eles estariam na mesma posição de seus colegas e não seriam vistos como pessoas que possuem outra fonte de renda. Essa era a única maneira que eles podiam liderar, mas agora isso não mais é verdade. E quando um trabalhador mineiro entrava em greve por um ano, a greve não se mantinha e o que de fato rompia esta - a despeito do fato de como permanecer em greve após um ano, que é um longo período de tempo...-, mas a coisa que começava a incomodar as pessoas era o atraso no pagamento do financiamento da casa própria e, consequentemente, a possibilidade de perdê-la. Dessa forma, consumismo, débito e a quebra do sindicalismo nos locais de trabalho são uma combinação estrutural de fatores, eu acho, que remontam à questão do propósito que você e meu amigo que trabalha na Unilever Best Food mencionaram. Ele diz que tudo que eles falam a você é: "continue fazendo as coisas e pense no dinheiro", e o único propósito de estar lá são os bons salários. Então, há um senso de que, se esse é o caso, o trabalho tornou-se algo simplesmente instrumental, e, então, se a parte mais importante de sua vida é vivida fora do trabalho, todas as coisas que eu mencionei anteriormente - sobre a centralidade do trabalho e a necessidade de uma sociologia do trabalho ser construída a partir de uma ideia de sociedade - se perdem. Mas eu tenho dúvidas se isso é totalmente verdadeiro.

Nós realizamos um projeto, até que grande, e parte do que fizemos foi "reconstruir" a vida das pessoas. Nós pedimos a elas, e eram sexagenários, que falassem de seus momentos-chave. O que nós encontramos nesses relatos, e são depoimentos 
completamente naturais e espontâneos, foram: as mudanças no trabalho, as mudanças de emprego e o fato de terem se tornado trabalhadores contratados. O local de trabalho desempenha um papel crítico na composição dos momentos que mudaram suas vidas - o trabalho e a família, na verdade. Essas foram as duas questões críticas que eles relataram. E isso você vai gostar, nós pedimos para as pessoas formarem círculos concêntricos e que falassem sobre quem era a pessoa mais próxima a elas para que as mapeássemos. Muitas pessoas perguntaram: "Eu posso colocar o meu cachorro aqui?". E dissemos: "Sim, você pode colocar seu cachorro aí". O cachorro ou o gato ficaram muito próximos às esposas ou aos maridos. Portanto, o papel do local de trabalho ainda é um elemento bastante crítico de uma vida, eu suponho. E eu penso que a sociologia do trabalho não tem sido desenvolvida de uma maneira que eu gostaria, nos oferecendo explicações de vida. Filmes fazem isso englobando esses elementos que você leu em Living with Capitalism. Você poderia pensar em escrever um relato: "Vivendo com o capitalismo flexível", sobre pessoas em mais de um trabalho, sobre toda essa mescla de atividades e sobre o que acontece quando algo dá errado. Quem você chama para fazer as coisas, quem cuida do gato, do cachorro, ou da criança, do filho ou da filha, todo esse tipo de coisas, sabe? Pegar o filho na escola, particularmente quando você é divorciado ou separado. Dizer que [a vida] é fragmentada é uma coisa, mas mostrar como as pessoas vivenciam a fragmentação e constroem um senso de si nesse contexto é outra coisa. Eu acho que isso é algo que nós poderíamos investigar - como o trabalho afeta isso. Vejo isso como algo que nos imagino fazendo.

Sim, então há uma maneira em que tudo isso pode ser reunido na qualidade de um fim da classe e o fim do trabalho, mas eu diria que nós precisamos reposicionar classe e trabalho dentro dessa nova forma de capitalismo. E eu não sei por que nós ainda não o fizemos.

\section{E o que Donald Roy de Fear Stuff, Sweet Stuff and Evil Stuff15 teria a nos dizer sobre o sindicalismo hoje?}

Bem, ele escreveu esse artigo, como você sabe, baseado em suas experiências em campanhas sindicalistas na Carolina do Norte, EUA, nos anos de 1970. E ele disse, e disso eu me lembro, que quando ele viu o sucesso da "abordagem do bem" [sweet stuff] e da "abordagem da ameaça" [fear stuff] ele ficou surpreso com os motivos que justificavam uma "abordagem do mal" [evil stuff]. Mas eles ainda fazem isso.

O que eu diria sobre o sindicalismo e o movimento sindical hoje é que esses três elementos permanecem vivos. A "abordagem do bem" é a ideia de você fazer coisas legais de modo que os membros de uma organização não quererão se unir ao sindicato. E a "abordagem do medo" é aquela em que, se você reclamar, será

\footnotetext{
${ }^{15}$ ROY, Donald. Repression and Incorporation: fear stuff, sweet stuff and evil stuff, management's defensiveness against unionism in the south. In: Nicholas, Theo (Org.). Capital and labour: a marxist primer. Glasgow, Fontana, 1980.
} 
demitido. A "abordagem do mal" é o que aconteceu aqui, na greve dos mineiros de 1984, quando um policiamento feroz foi combinado com o uso de agentes provocadores e infiltrados nos sindicatos. Recentemente descobrimos que a Força Policial Metropolitana possui uma divisão chamada Divisão Especial de Documentação [Special Documentation Squad] que está envolvida no uso de oficiais de polícia disfarçados que se infiltram nos sindicatos e nos grupos de protesto, muitas vezes iniciando atividades militantes e ilegais. Houve um número de casos publicados, relacionados a grupos de protestos, em que esses oficiais, passando-se por ativistas, tiveram relação sexual com mulheres e tiveram filhos com elas, mesmo sendo policiais e casados. Em um encontro recente com um ex-funcionário dessa divisão, ficou-se sabendo que eles haviam se infiltrado em cinco sindicatos. Essa seria a "abordagem do mal" de Donald Roy, penso eu.

Mas, como eu disse, as outras abordagens têm obtido tamanho sucesso que alguém pode se perguntar por que se incomodar com isso, porque de um modo ou de outro o número de trabalhadores associados aos sindicatos, no Reino Unido, caiu de $75 \%$ para $28 \%$ da força de trabalho. Antigamente, quando você embarcava em um navio ou trem, ou mesmo fazendo compras, quase certamente você se deparava com alguém que havia sido sindicalista. Hoje em dia, os sindicalistas têm se tornado minoria, talvez uma espécie em extinção; e em grande número no setor público, que agora está sob esse enorme ataque. Esse declínio certamente está associado à desindustrialização: com a perda de quase três milhões de empregos no setor manufatureiro, muitos dos quais pertenciam a trabalhadores sindicalizados. A perda desse núcleo sindicalizado da força de trabalho teve um grande impacto. Mas, ao lado disso, há um ataque ideológico sobre o coletivismo e sobre a própria natureza do sindicalismo como uma força de oposição. Isso foi fomentado pelo Partido Conservador quando oposição e colocado em prática quando no governo, com mudanças dramáticas na situação legal dos sindicatos no país. Essas leis permaneceram inalteradas durante o governo da nova esquerda, com Blair e Brown, que aceitaram a mesma análise do fim do coletivismo e do sindicalismo.

É interessante notar que a Fundação Margaret Thatcher criou um acervo no Churchill College na Universidade de Cambridge que agora está digitalizado e contém correspondências e atas de reuniões que ocorreram nos anos de 1970 e 1980. Um comitê criado por eles na década de 1970, chamado “Stepping Stones", é particularmente revelador de sua abordagem em relação ao sindicalismo. Isso foi sobretudo obra de um dos assessores da Senhora Thatcher e de um diretor sênior da Unilever (novamente). Eles defendiam, entre outras coisas, que um discurso tinha que ser elaborado visando enfraquecer os sindicatos por meio da separação dos líderes sindicais de seus membros. Uma parte disso visou mudanças nas regras eleitorais para cargos, nas votações para deliberar sobre greves e em outras ações. Mas, uma outra parte, dizia respeito ao modo no qual os líderes sindicais passaram a ser referidos. A agenda da "Stepping Stones" buscava descreditar as lideranças sindicais, divulgando seus estilos de vida e descrevendo-os, de modo pejorativo, como "chefes" e "barões" e por aí vai. Tudo isso sendo ventilado na mídia via contatos do Partido Conservador com a imprensa. Tudo isso porque o 
comitê tinha ciência de que os líderes sindicais formavam o único grupo social que poderia organizar uma oposição aos seus planos para introduzir a revolução neoliberal. Por acreditarem em um outro tipo de economia esses líderes sindicais tinham que ser separados de seus afiliados. Em grande medida essa estratégia obteve sucesso.

Dessa forma, há um processo que contribui para a seguinte situação: desindustrialização e neoliberalismo juntos, tendo um sério efeito enfraquecedor [para o sindicalismo]. Ao mesmo tempo, há um processo de mudanças significativas na economia e na forma de emprego, o que tem causado dilemas e dificuldades para o recrutamento de sindicalizados, bem como no que tange às estratégias de organização [do movimento sindical]. O Reino Unido vê sua nova (e reduzida) base manufatureira sendo dominada por empresas estrangeiras - e não apenas da Europa ou dos Estados Unidos. A indústria de carros agora é dominada por japoneses com algum envolvimento de empresas indianas e chinesas. As empresas japonesas tendem a usar "abordagem do bem" como uma maneira de reduzir o nível de afiliação sindical, tentando fazer com que os trabalhadores se identifiquem com a empresa e não com o sindicato. Esse contexto de mudanças rápidas convida-nos a uma discussão ampliada da ideia de Michael Burawoy ${ }^{16}$ de "regimes de emprego".

Diante disso, os sindicatos tentam mudar o foco. Dado que seu papel principal de "negociador" das condições econômicas da classe trabalhadora foi desafiado e severamente comprometido, eles passaram a focar na "organização". Isso quer dizer "recrutamento": sua principal preocupação passou a ser: estancar a hemorragia de afiliados. Em certa medida isso foi bem-sucedido e a queda íngreme da taxa de afiliação diminuiu. Hoje - especialmente quando estão lidando com os ampliados ataques ao setor público - eles se consideram organizações de "campanha". O que é um empreendimento novo e interessante: levar o sindicato para além do local de trabalho e para as ruas para fazer campanha, não simplesmente por "empregos", mas para os serviços que dependem desses empregos.

\section{Trata-se apenas de uma associação temporária? É essa a ideia de campanha?}

Fazer campanha em torno de assuntos que afetam seus membros. No setor público, quando eles fazem campanha em torno da ideia de empregos do setor público, deixam claro que se trata de empregos importantes, que o futuro do serviço público é um assunto importante. Em vez de apenas dizer: "nós queremos um aumento de 5\%", eles dizem: "nós queremos defender e fazer campanha para o setor público por melhores hospitais e escolas" e assim por diante. E eles também ligam seu discurso a assuntos que podem ser considerados como não sindicais, como campanha por moradia e outras coisas. Eles se veem como organizações de defesa dos pobres e marginalizados e dos trabalhadores em todos os aspectos de suas vidas.

${ }^{16}$ BURAWOY, Michael. The politics of production: factory regimes under capitalism and socialism. Londres, Verso, 1990. 
É claro que os sindicatos estão agora em uma posição muito mais frágil, mas eles ainda possuem recursos e mais de cinco milhões de membros. Portanto, ainda possuem força para um acerto de contas se assim o desejarem. Mas eles precisam resolver sua relação com o Partido Trabalhista. Hoje a maioria dos sindicatos ainda é afiliada ao Partido Trabalhista, mas um número considerável deles tem deixado esse partido, enquanto outros nunca se afiliaram - e há quem afirme que eles se encontram em melhor posição para apoiar a luta dos trabalhadores, por poderem apoiar qualquer partido que queiram. Podem apoiar os verdes ou os nacionalistas ou o que quer que seja.

\section{Tudo menos o Partido Trabalhista?}

Bem, muitos deles estão no Partido Trabalhista, certamente, mas a relação entre o partido e o sindicato tem se tornado tensa com pessoas de ambos os lados (do sindicato e do partido) dizendo que seria melhor para os dois se eles se separassem. Entretanto, isso não aconteceu ainda. Na perspectiva dos sindicatos o propósito da afiliação é alcançar um Governo Trabalhista que favoreça o trabalhador e favoreça os sindicatos. Mas a experiência do governo da nova esquerda enfraqueceu essa alegação, uma vez que muito pouco foi feito para fortalecer a posição dos sindicatos naquele período. Portanto, os sindicatos têm buscado obter mais controle das políticas partidárias, o que tem provocado um clamor: "Eles querem controlar o partido, eles querem controlar o partido!". Para o qual os sindicatos respondem: "Sim, isso é verdade! Fomos nós que o criamos. É o nosso partido! Este é o partido trabalhista!".

\section{Isso faz sentido?}

Sim, e na verdade é uma tremenda ironia o fato de eles terem criado o Partido Trabalhista com o propósito de controlar o capital e para tê-lo como um partido para o trabalho e o que se tornou claro foi que ele não pode ser esse tipo de Partido do Trabalho.

\section{Ele não pode?}

Bem, o novo Partido Trabalhista esteve no governo por 13 anos e eles nada fizeram para alterar as leis sindicais introduzidas por Thatcher. Eu não consigo ver como eles podem afirmar se tratar de um partido do trabalho. E agora parece que temem dizer coisas positivas sobre os sindicatos ou sobre as pessoas que estão em greve. Temem que a imprensa se volte contra eles. Eles de fato temem isso! A situação aqui não é tão ruim quanto a do Brasil, mas é ruim o suficiente. Aqui a maioria da imprensa pertence ou a indivíduos privados reacionários ou a companhias privadas reacionárias. Portanto, a agenda subjacente é profundamente de direita. Nós ainda temos a BBC e eles temem sair muito da linha do governo, de todo modo a história que esta segue parece ser ditada pelos jornais. Dessa forma, basicamente, tem sido muito difícil para os sindicatos. 
Você tem trabalhado com pesquisadores brasileiros como Marco Aurélio Santana, José Ricardo Ramalho, Leonardo Gomes Mello e Silva, Rodrigo Santos, entre outros. Você poderia contar como começou sua relação com o Brasil e o que você deixou e ganhou em sua ligação com essas pessoas? Quais foram os estudos mais importantes que você desenvolveu com seus colegas brasileiros?

Eu fui ao Brasil pela primeira vez em 1989. Havia me mudado de Durham para Manchester para ser professor titular daquela universidade junto com Teador Shanin, em 1987. Ele foi convidado a ir ao Museu Nacional, no Rio, para ficar alguns meses lá. Quando ele voltou, sugeriu que eu fizesse o mesmo. As visitas foram organizadas via Consulado Britânico e eu fui convidado por Moacir Palmeira a ir ao Museu Nacional. Ele era um bom rapaz e tinha organizado algumas aulas para mim no Museu Nacional e também na UFRJ, USP e Unicamp. Eu encontrei várias pessoas naquele verão, incluindo José Sérgio Leite Lopes e José Ricardo Ramalho, que estava para vir a Londres, para o Instituto Latino-Americano. Encontrei Chico de Oliveira pela primeira vez. E então, na Unicamp, encontrei Michael Hall e Ricardo Antunes, entre outros. Foi uma época muito prazerosa e o começo de um período de intensa interação. Pessoalmente, fui convidado a retornar para dar aulas na Unicamp - onde fui ciceroneado por Leôncio Martins Rodrigues - e no Instituto, no Rio, com meu amigo José Ricardo.

De modo geral, nós organizamos uma série de intercâmbios de funcionários entre a Universidade de Manchester e as universidades de Campinas (Unicamp), Rio de Janeiro (UFRJ) e de João Pessoa (UFPB). Havia também brasileiros cursando doutorado no Reino Unido e eu fui um dos examinadores de alguns deles - um deles sendo Maria Célia da USP, que tinha trabalhado com [Eric John Ernest] Hobsbawm, em Londres, sobre a questão do trabalho no Estado Novo. Assim, essas conexões e amizades foram sendo construídas e se sobrepuseram. José Ricardo passou um ano comigo na Universidade de Manchester, com seu filho Emiliano, e nós até assistimos ao futebol juntos. Leonardo Silva ficou um ano comigo em Cardiff. Ele encontrou Priscila lá e casaram-se no ano passado. Também se tornou um especialista em bares galeses. O CNPq proporcionava um esquema de "sanduíche", em que os alunos passavam um ano no Reino Unido. Foi assim que eu pude trabalhar com Paulino Santos, Gino, Marcos e Rodrigo e alguns outros. E foi assim que eu o conheci.

Eu gostei muito do Brasil e das discussões que tivemos durante os anos de 1990, que foram bastante aprofundadas. Um dos temas discutidos, que eu já mencionei, era a ideia da formação da classe. Minha pesquisa nas minas britânicas no século XIX e as questões aventadas sobre os trabalhadores forçados, tendo uma consciência coletiva e uma conscientização, articulavam-se com as pesquisas históricas no Brasil... Michael Hall e seus estudantes Gino Negro e Paulino Santos estavam investigando o impacto dos imigrantes que iam do Nordeste para São Paulo e que construíram uma nova classe trabalhadora na região. Naquela época, os arquivos referentes aos militares estavam sendo abertos e havia muito da "abordagem do 
mal" lá. Havia trabalhadores espiões relatando o que os trabalhadores faziam em suas ocupações - eles eram carpinteiros - e eles de fato possuíam um senso de trabalho, de exploração e de coletivismo. Portanto, essas discussões foram muito excitantes.

Naquela época, eu havia escrito o livro Masters and Servents sobre o sindicalismo. José Sérgio certamente já tinha escrito seu enorme livro sobre o paternalismo nas fábricas têxteis do Recife, que tratava da maneira como o paternalismo afetou as relações e a consciência de classe. Quando José Sérgio e Moacir vieram a Manchester, como parte do esquema de intercâmbio, nós visitamos um museu que ficava num velho moinho de algodão, no sul da cidade, um lugar chamado Style. Ambos notaram as similaridades deste com os moinhos que eles haviam visitado no Nordeste do Brasil. Portanto, Reino Unido e Brasil continuavam ligados de uma outra forma. Michael Hall falou como as nossas sessões de Campinas aproximavam nossos pensamentos sobre a história política do trabalhismo britânico e do trabalhismo brasileiro por meio de comparações que nós realizamos entre o PT e o Partido Trabalhista Britânico.

Um outro assunto de nossas conversas referia-se às estratégias do capital e particularmente à capacidade das firmas multinacionais de se tornarem móveis e operarem em diversos lugares, rompendo seus laços com o Estado para competir umas com as outras por trabalho via diferentes tipos de arranjos financeiros. Em relação à Britânia nós olhamos para a capacidade de o capital se trasladar, e isso ligava-se às teorias da globalização num tempo onde o Brasil estava abrindo suas portas para essas firmas. Um exemplo disso ocorreu em Resende, onde a Volkswagen abriu uma nova fábrica. Durante minha estada no Rio, eu havia visitado a fábrica de Resende algumas vezes, uma com um estudante alemão, Tomke Taske, que me conseguiu uma visita aos metalúrgicos de lá, que se tornaram gêmeos idênticos dos metalúrgicos que trabalharam em Ebbbw Vale, uma cidade do sul do País de Gales, onde eu cresci e onde trabalhei, por um curto período de tempo e antes de entrar na universidade, na fundição e na parte de metalurgia da fábrica.

A fábrica de Resende era idêntica, possuindo exatamente os mesmos processos, de cabo a rabo. Era como se eles tivessem pego a planta de Ebbw Vale e colocado em Resende. Portanto, no setor têxtil e metalúrgico nós vimos essas transferências e paralelos. E Resende (beneficiada por incentivos fiscais) tornou-se um polo industrial com novas fábricas automobilísticas alocadas lá em vez de no $\mathrm{ABC}$ paulista. Eu estive na fábrica da Volkswagen com José Ricardo e nós ficamos intrigados ao descobrir que a companhia estava usando o local para experimentar uma nova maneira de organizar a linha de montagens das vans, tendo por base a "modularização". Isso envolvia a subcontratação de firmas, que se responsabilizavam pela contratação do trabalho e pela instalação de seus equipamentos na van, na linha de montagem. Assim, nenhum dos trabalhadores de Resende era empregado da Volkswagen ${ }^{17}$. Esta simplesmente tinha a estrutura predial e a marca das vans.

${ }^{17}$ Vide: ABREY, Alice; BEYNON, Huw; RAMALHO, José Ricardo. The dream factory': VW's modular production system in Resende, Brazil. Work, Employment \& Society. Londres, v. 14, n. 2, 2000, pp. 265-282. 
Ela era também responsável pelas negociações presenciais com os sindicatos. Portanto, aqui tínhamos o exemplo de uma companhia automobilística estabelecida com uma marca claramente identificável reduzindo seu envolvimento direto no processo produtivo. Ford, à época, estava ganhando mais dinheiro com o arrendamento de carros do que com a produção destes. E isso sugere uma mudança no sistema produtivo com as companhias fazendo uso de localidades distantes da Europa e América para esses tipos de locais experimentais. Isso foi antes de 2008 e do grande colapso, quando as companhias estado-unidenses em particular precisaram ser socorridas.

$\mathrm{Na}$ minha primeira visita ao Brasil, visitei as fábricas do $\mathrm{ABC}$ com Gino e em outra ocasião conversei com uma liderança da CUT da fábrica da Ford de lá, com José Ricardo. Quando nós nos introduzimos ele me contou que ele esteve em Liverpool e conhecia pessoas da fábrica de Halewood que eu também conhecia. O comitê unificado dos representantes dos trabalhadores tinha organizado um encontro de representantes de todas as plantas da Ford do mundo, que ocorreu em Liverpool. Eles tinham estudantes envolvidos que realizavam a tradução simultânea, e por aí vai. E (como eu disse anteriormente) esse foi o ponto áureo da organização de base na indústria de carros, nos anos de 1970...

\section{Impressionante! Eu não sabia disso}

Foi surpreendente iniciar uma conversação em que ele disse "quem você conhece da Ford?" e eu contei a ele. Assim eu ganhei crédito porque conhecia as pessoas certas, as pessoas de Liverpool que ele conhecia. E ele também conhecia partes da cidade de Liverpool. Dessa forma, estávamos em São Paulo conversando sobre Liverpool, sobre onde eu vivi e por aí vai. $\mathrm{O}$ encontro deixou uma boa impressão sobre ele e era possível ver na maneira como falava que o encontro com outros trabalhadores da Ford simplificava as coisas para eles, no sentido de todos compreenderem os problemas envolvidos em se trabalhar para a companhia. Portanto, eu acho que é incrível - talvez você possa até mesmo ver nisso um potencial, o começo de um movimento de classe global. Todos pertenciam formalmente à organização, mas eles se encontravam, como uma organização, para combater a companhia.

\section{Interessante!}

Isso foi nos anos de 1980 ! $\mathrm{E}$, em alguma medida, isso se foi. $\mathrm{E}$ agora que a globalização se tornou mais desenvolvida nós precisamos mais do que nunca desses tipos de organização para preencher as lacunas, para ligar os pontos.

Recebido em: 14/10/2015

Aceito em: 20/11/2015

\section{Como citar este artigo:}

MARTINS, Fernando Ramalho; RANGEL, Felipe. Huw Beynon: uma sociologia pública do trabalho. Contemporânea - Revista de Sociologia da UFSCar. São Carlos, v. 6, n. 1, jan.jun. 2016, pp. 237-258. 